\title{
Does differential C-heterochromatin content affect chromosome pairing in octoploid triticale?
}

\author{
Araceli Fominaya* and \\ Juan Orellana†
}

\author{
* Departamento de Biología Celular y Genética, \\ Universidad de Alcalá de Henares, Apdo. 20, \\ Alcalá de Henares, Madrid, Spain. \\ $\dagger$ Departamento de Genética Agraria, \\ Escuela Técnica Superior de Ingenieros Agrónomos, \\ Universidad Politécnica, Madrid, Spain.
}

Three octoploid triticales with different amounts of $\mathrm{C}$-heterochromatin in the rye chromosomes but with the same wheat genetic background have been analyzed at meiosis. The reduction of rye-rye and wheat-wheat homologous pairing observed at metaphase $I$ in the triticales with respect to their corresponding rye and wheat parents does not follow any relationship with the presence or absence of $\mathbf{C}$-heterochromatin in the rye genome or in specific rye chromosomes.

\section{INTRODUCTION}

It has been shown in several studies that in both hexaploid and octoploid triticale there are many meiotic irregularities affecting the rye and wheat chromosomes, and different theories have been suggested to explain such behaviour (see Gupta and Priyadarshan, 1982). It is worth mentioning the special relevance of those hypotheses which assume that the C-heterochromatin can play an important role in the meiotic instability found in triticale and wheat-rye hybrids. It has been said that the presence of telomeric or intercalary Cbands can reduce chromosome pairing not only on the chromosomes carrying it but also on others (Thomas and Kaltsikes, 1974, 1977; Merker, 1976). It has always been believed that C-heterochromatin affects rye to a greater degree than wheat chromosomes and the intensity with which such an effect acts is positively correlated with the size of C-heterochromatin blocks (see Gupta and Priyadarshan, 1982).

These findings have led to the use of rye stocks with low amounts of heterochromatin to form new triticales (see Kaltsikes et al., 1984). However, there is some evidence indicating that if the Cheterochromatin plays some role on chromosome pairing this does not act following a simple model (Lelley and Larter, 1980; Kaltsikes et al., 1983).

The aim of this work was to study the influence of some factors on meiotic pairing in octoploid triticales with different heterochromatin content but the same wheat genetic background.

\section{MATERIAL AND METHODS}

Three types of octoploid triticales obtained from crosses between hexaploid wheat $c v$. "Chinese Spring" and three lines of diploid rye with different C-heterochromatin contents formed the material for this study. The rye lines were the open pollinated variety $c v$. "La Raña" (Lograsán, Cáceres) and the two inbred lines $\mathrm{R}$ (123) and $\mathrm{J}$ (15). The wheat-rye hybrid seeds obtained from these crosses were germinated in Petri dishes at $20^{\circ} \mathrm{C}$ in the dark. Subsequently, the seedlings were transferred into jiffy-pots and treated with $0 \cdot 10$ per cent colchicine, with 3 per cent DMSO for five hours at room temperature at the 3-5 leaf stage (Thomas and Pickering, 1979). Spikes of these colchicinetreated plants were allowed to self pollinate in order to obtain amphiploids. Chromosome counts on these progenies were made from primary roots pretreated with cold water $0-4^{\circ} \mathrm{C}$, fixed in $1: 3$ acetic acid: ethanol, and stained by the standard Feulgen procedure. For meiotic studies, anthers from euploid plants were fixed in 1:3 acetic acid: ethanol and stored $0-4^{\circ} \mathrm{C}$ for $1-4$ months. The fixed material was squashed and stained following the Giemsa C-banding technique described by Jouve et al., 1980. 


\section{RESULTS}

In triticale wheat and rye chromosomes can be distinguished because wheat chromosomes show a different $\mathrm{C}$-banding pattern from the rye chromosomes. In addition, nine wheat chromosome pairs can be distinguished at meiosis: seven from the B genome and 4A and 7A (Ferrer et al., 1984); and four rye pairs: $1 R, 4 R, 5 R$, and $6 R$ (fig. 1 ). In the
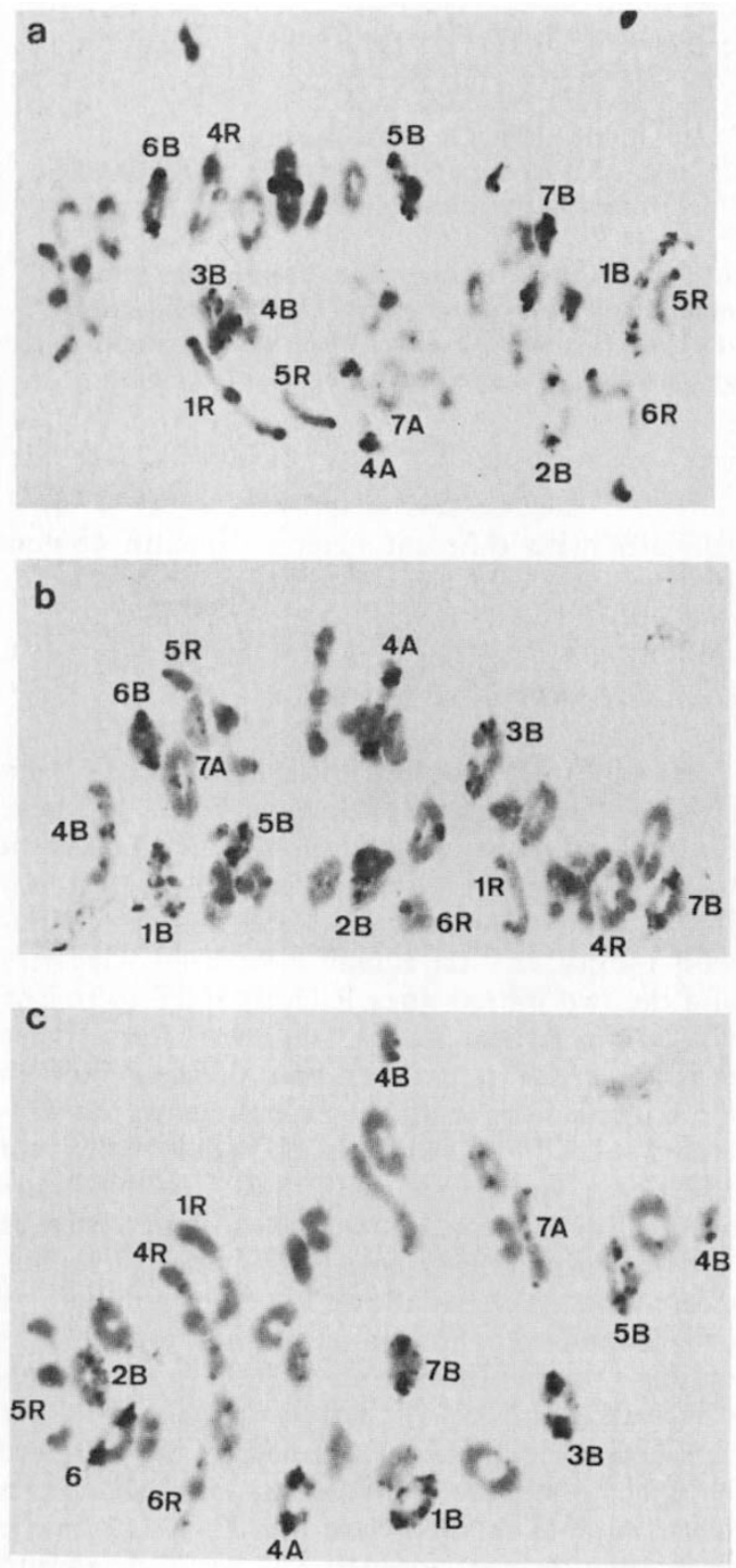

Figure 1 Photomicrographs of PMCs at first metaphase of the three octoploid triticales analyzed. CSJ (a), CSRa (b), and CSR (c). open pollinated population, La Raña, only $1 \mathrm{R}$ and 6 $\mathrm{R}$ chromosome pairs were distinguished due to polymorphisms.

In all cases four meiotic configurations could be distinguished at first meiotic metaphase for each of the identified chromosomes, namely, ring bivalents, open bivalents with either the short or the long arm bound and univalent pairs (fig. 1(a), (b), (c)). For the remaining chromosomes only ring and open bivalents or univalents could be ascertained.

The three rye lines used for this study showed a different $\mathrm{C}$-banding pattern. Chromsome $1 \mathrm{R}$ of line $J$ possessed two prominent $\mathrm{C}$-heterochromatin blocks in the telomeres of both arms, whereas lines $\mathrm{R}$ and $\mathrm{Ra}$ did not. Chromsome $4 \mathrm{R}$ had a medium sized C-band in the short arm in line $\mathrm{J}$ but this was not present in lines $\mathrm{R}$ and $\mathrm{Ra}$. Chromosome $5 \mathrm{R}$ showed a small $\mathrm{C}$-band in the telomere of the short arm in lines $\mathrm{J}$ and $\mathrm{Ra}$, whereas in line $\mathrm{R}$ such a band was absent. Chromosome $6 \mathrm{R}$ possessed a prominent telomeric block in the short arm in line $\mathrm{J}$, medium in $\mathrm{Ra}$ and small in $\mathrm{R}$.

The analysis of the karyotype in all lines indicates that, in general, line $J$ was the most heterochromatic and inbred line $\mathrm{R}$ the most euchromatic (fig. 2(a), (b)). Obviously, these differences were maintained in the octoploid triticales obtained from these lines.

It has been assumed in previous studies that the presence of telomeric C-bands reduces rye chromosome pairing in triticale (see Gupta and Priyadarshan, 1982). In agreement with these previous data, a high frequency of univalents and rod rye bivalents was observed at metaphase $I$ in all cases. However, the three triticales analyzed showed a very similar mean number of rye-rye bound arms per cell, although significant deviations were detected when statistical tests were performed (table 2). In the same way, the mean number of rye-rye homologous pairings per cell was very similar for CSJ with respect to that found in its parental rye $(\mathrm{J})$, and there was no significant deviation between the two means (table 2). However, significant differences were observed from such a type of comparison for the other two triticales analyzed (table 2 ).

On the other hand, the mean number of wheatwheat homologous pairings observed at metaphase I in all triticales was lower than that observed in hexaploid wheat $c v$. "Chinese Spring" (table 2). In fact several wheat chromosomes arms showed lower pairing frequency than some rye ones (table 1). However, as in rye, the mean amount of wheat homologous pairing per cell observed in the three 

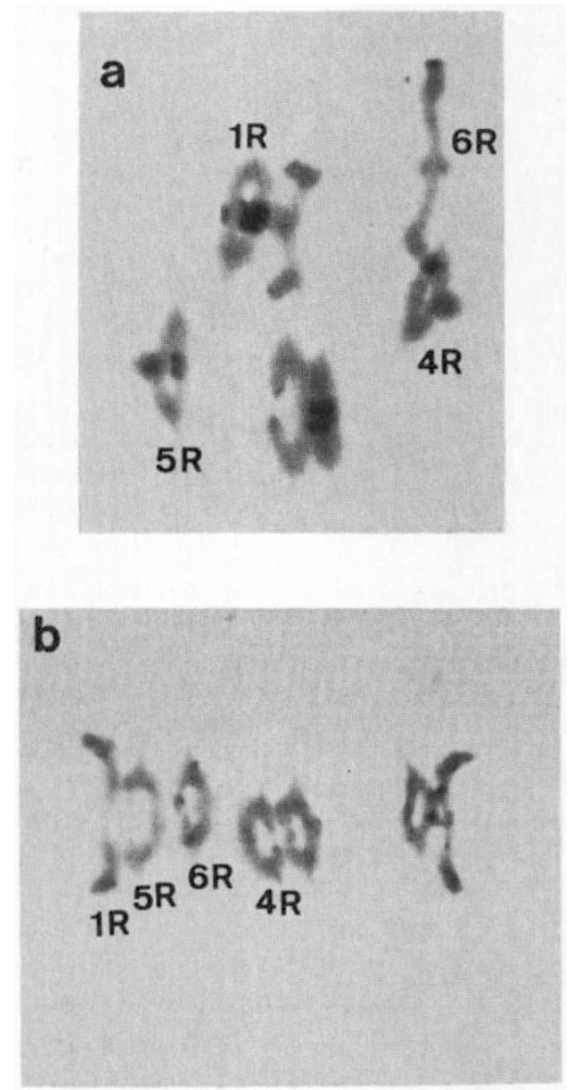

Figure 2 Meiotic configurations of diploid ryes with different C-heterochromatin contents. J (a) and R (b).

triticales was very similar and significant differences were only detected between CSJ and CSRa (table 2).

If the effect of the decrease in pairing acts in a general way, one can expect that the relative contribution of each chromosome to the total number of bonds would be constant, i.e., the percentage with which each arm contributes to the total number of bonds must be the same in spite of pairing frequencies not being the same in different plants. When comparisons of the number of bound arms among the different triticales and between each triticale and its parental rye were performed by contingency $\chi^{2}$ tests significant deviations were only observed in a very few cases (see table 1 ).

\section{DISCUSSION}

Many cytogenetic studies have demonstrated that in triticale and wheat-rye hybrids considerable meiotic irregularities occur. To explain the pairing failures observed in triticales many authors have assumed that the telomeric heterochromatin of rye chromosomes in single or double dosages reduces meiotic pairing of the chromosomes carrying it (Thomas and Kaltsikes, 1974, 1976) and that this effect is correlated with the size of the block (Merker, 1976).

Thomas and Kaltsikes (1974) have suggested that the decrease of pairing in triticales is produced by an interference between late DNA replication of telomeric heterochromatin in rye chromosomes and chromosome pairing initiation. This assumption was supported because it was believed that meiotic pairing initiation is restricted almost entirely to telomeric regions in rye. So, meiotic pairing in rye could not be initiated until the DNA replication process was finished. If the C-heterochromatin content of rye genome is the only or the most important cause responsible for the low pairing found in rye chromosomes one would expect, in the present case, that triticale plants in which line $J$ is included (CSJ) should show a higher frequency of meiotic irregularities than those made from the $\mathrm{R}$ line, since the former possesses more heterochromatin and the CSRa triticale should show an intermediate behaviour. However, the three triticales analyzed in this study show a very similar mean number of rye-rye bound arms per cell and no significant difference was found when the triticales were compared (CSJ-CSR).

It has also been reported that the interference between DNA replication and pairing becomes critical in triticale but not in rye itself (Merker, 1976; Naranjo and Lacadena, 1980). If this was so, one should expect that the rye genome in CSJ would show the most deviant data with respect its parental diploid rye $(\mathrm{J})$, and subsequently, the fit between CSR and line R should be much better. However, the actual results are clearly opposite to the expected ones (table 2).

The decrease in pairing detected in CSRa with respect to its parental rye can be explained in another way. $\mathrm{Ra}$ is an open pollinated population and it is well-known that the homozygosity produced by inbreeding leads to drastic reductions in chromosome pairing (Lamm, 1936; Rees, 1955). Obviously, rye chromosomes are in the homozygous condition in the triticale following colchicine treatment and consequently the rye genome would be considered to be very similar to that of an inbred line. So, a rye low pairing frequency is expected in triticale with respect to the open pollinated variety from which it was derived.

Roupakias and Kaltsikes (1977) inferred that C-heterochromatin present on one chromosome 
Table 1 Number of bonds formed by each identified bivalent arm in the triticales and inbred rye lines. The percentage for each bivalent arm to form a bond appears in brackets. Contingency $\chi^{2}$ tests concern the relative contribution of each chromosome arm to the total wheat-wheat or rye-rye number of bonds

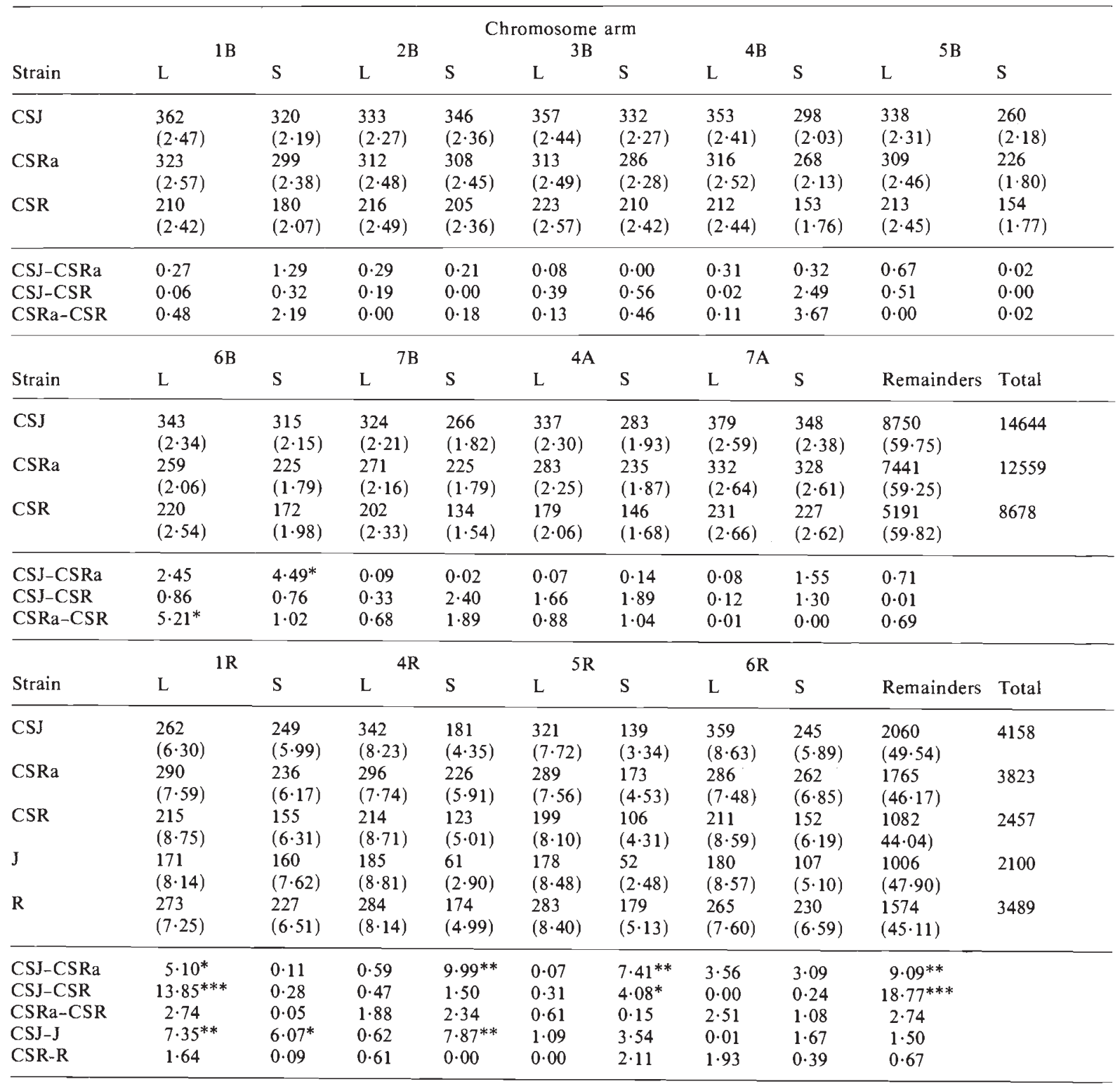

\footnotetext{
* Significant at the level of 5 per cent.

** Significant at the level of 1 per cent.

*** Significant at the level of $0 \cdot 1$ per cent.
}

can influence the chromosome pairing of other chromosomes. If this is true, the rye genome should reduce chromosome pairing in the wheat genome as was observed in this study. However, if this decrease was correlated with the amount of Cheterochromatin present in rye genomes then the biggest decrease in wheat-wheat homologous pair- ing should correspond with the CSJ triticale and the smallest with CSR. The data are in disagreement with such an assumption because the mean number of wheat-wheat homologous pairing found is the same for the two triticales. On the other hand, the consistency of the percentage which each chromosome contributes to the total 
Table 2 Mean number of bound arms per cell at metaphase $I$ in the triticale and rye plants studied. The wheat-wheat and rye-rye homologous pairing among the three triticales and between each triticale and its parental wheat or rye are also compared

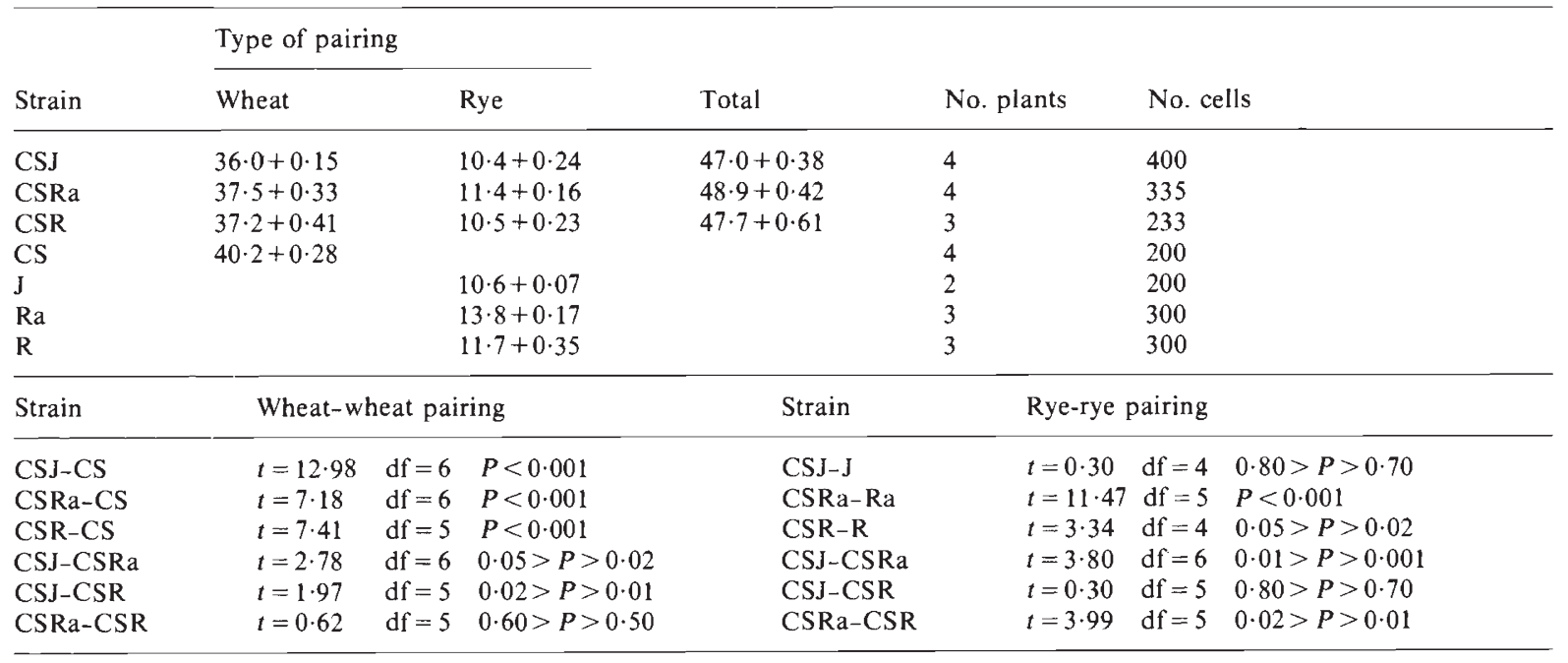

meiotic pairing in all triticales and its parental rye indicates that the reduction of pairing does not affect specific chromosomes or wheat genomes, and is not related with heterochromatin content (table 1).

Previous studies of isogenic lines of triticale with or without $\mathrm{C}$-heterochromatin in specific rye chromosome arms (6RS and 7RL) have indicated that the absence of heterochromatin increases chromosome pairing (Merker 1976; Roupakias and Kaltsikes, 1977). However, analysis of the 6RS chromosome arm (7RL is undistinguishable) in the present study indicates that there is no correlation between the presence or absence of C-heterochromatin and chromosome pairing. The mean number of bonds per cell among the three triticales and between each triticale and its parental rye were not significantly different when t-tests were performed (see table 1). Similar results were obtained from the comparisons with others arms. So, if the C-heterochromatin decreases pairing of the chromosome arm carrying it then it would be expected that the contribution of bonds would be lower in triticale than in the parental rye for those arms with C-bands. This seems to be true for chromosome $1 \mathrm{R}$ when CSI and $\mathrm{J}$ are compared, but for the short arms of chromosomes $4 R$ and $5 R$ the opposite result was found (table 1).

The analysis of individual chromosomes is probably more accurate than that using entire genomes but it could lead to serious discrepancies. In fact, Kaltsikes et al. (1983) found a negative correlation between the number of univalents and the presence of heterochromatin in the short arm of chromosome 6R, and they concluded that an increase in heterochromatin on such a chromosome arm would lead to higher meiotic stability in triticale. This is exactly the opposite of the expectations based on earlier studies (Kaltsikes and Roupakias, 1976; Roupakias and Kaltsikes, 1977; Schlegel, 1979; Kaltsikes and Gustafson; 1982).

Most studies attribute the lack of pairing of rye chromosomes to terminal heterochromatic bands. However, there are many discrepancies. For example Schlegel (1979) found a highly significant negative correlation between the amount of telomeric heterochromatin present on rye chromosomes and the meiotic stability of amphidiploid plants obtained from "Chinese Spring" and four wild rye species. However, Kaltsikes et al. (1983) found that in eight wheat-Secale amphiploids obtained from Cocorit wheat and wild rye species there was no clear pattern of pairing related with the C-heterochromatin, DNA content or chromosome length. These authors explain their results under the assumption that the several species utilized would differ from each other by at least three translocations as it has been pointed out by Stutz (1972). In addition, these species could also differ in the genetic control of chromosome pairing. The structural or genetic differences could influence chromosome pairing, and therefore triticales obtained from different rye species cannot be usefully compared.

The interference between the late DNA replication of heterochromatin and telomeric initiation pairing could explain the meiotic instability 
observed in triticale because this interference would mainly affect rye chromosomes. Therefore univalent formation in the rye genome should be higher than in wheat as observed here. However, recent studies have demonstrated that in both rye and wheat there are multiple pairing initiation sites in each bivalent and there is not a simple zipping up initiation pairing from a few sites (AbirachedDamency et al., 1983; Jenkins, 1983, Gillies, 1985; Holm, 1986). With this new evidence one cannot expect a correlation between the presence of Cheterochromatin and pairing failures in the rye genome.

The present results indicate that heterochromatin content does not necessarily affect meiotic pairing. It is possible that C-bands could modulate gene activity as suggested by Appels (1982), but if it is so, its effect was not detectable in our case. Probably, cryptic interactions between wheat and rye chromosomes can explain the results found. In many cases, it has been reported that wheat chromosomes produce a decrease in rye homologous pairing (Riley and Chapman, 1957; Lacadena, 1967; Naranjo et al., 1979). Lelley and Larter (1980) have suggested that the genotypes of wheat and rye parents influence chiasma frequency in wheat-rye hybrids. They observed increased pairing when an inbred line parent was used and concluded that the genetic constitution of the rye parent and its specific combining ability with the wheat genotype influences the meiotic behaviour in triticale.

One can expect genotypic differences between the three lines of rye used in this study, and therefore differences between the three triticales. Some differences have been detected between CSJ, CSRa and CSR although these were weak and the results shown in tables 1 and 2 indicate that all triticales have a similar meiotic behaviour. On the other hand, Müntzing (1957) has suggested that the forced homozygosity of allogamous rye was the reason for the univalent formation in triticale, and therefore inbred rye lines should be used in new syntheses to avoid forced inbreeding in the rye complement. However in the present study the triticales produced with inbred lines do not have a more stable meiosis than CSRa. This indicates that the adaptation to homozygosity in obtaining the inbred lines does not lead to more meiotic regularity in triticale production. Moreover, one can conclude that the interactions do not affect wheat and rye genomes in the same way. Similar results have been observed in Aegilops-Secale amphiploids (Cermeño et al., 1985).

\section{REFERENCES}

ABIRACHED-DAMENCY, M., ZICKLER, D. AND CAUDERON, Y. 1983. Synaptonemal complex and recombination nodules in rye (Secale cereale). Chromosoma, 88, 299-306.

APPELS, R., 1982. The molecular cytology of wheat-rye hybrids. Int. Rev. Cytol., 80, 93-132.

CERMEÑO, M. C., CUÑADO, N. AND ORELlANA, J. 1985. Meiotic behaviour of Un, D, and R genomes in the amphiploid Aegilops ventricosa-Secale cereale and its parental species. Theor. Appl. Genet., 70, 679-683.

FERRER, E., GONZALEZ, J. M. AND JOUVE, N. 1984. The meiotic pairing of nine wheat chromosomes. Theor. Appl. Genet., 69, 193-198

GILlIES, C. B. 1985. An electron microscopic study of synaptonemal complex formation at zygotene in rye. Chromosoma, 92, 165-175.

GUPTA, P. K. AND PRIYADARShAN, P. M. 1982. Triticale: Present status and future prospects. Adv. Genet., 21, 255-345.

HOLM, P. B. 1986. Chromosome pairing and chiasma formation in allohexaploid wheat, Triticum aestivum analyzed by spreading of meiotic nuclei. Carlsberg Res. Commun., 51, 239-294.

JENKINS, G. 1983. Chromosome pairing in Triticum aestivum cv. "Chinese Spring". Carlsberg. Res. Commun., 48, 255283.

JOUVE, N., DIEZ, N. AND RODRIGUEZ, M. 1982. C-banding in $6 \mathrm{x}$-triticale $\times$ Secale cereale $\mathrm{L}$. Hybrid cytogenetics. Theor. Appl. Genet., 57, 75-79.

KALTSIKES, P. J. AND ROUPAKIAS, D. G. 1976. Heterochromatin and chromosome pairing in triticale. Crop. Sci. Soc. Am. Ann. Meet., Houston. p. 54 (Abstr.).

KALTSIKES, P. J. AND GUSTAFSON, J. P. 1982. Factors affecting chromosome pairing in triticales. Inter. Symp. on New Genetic Approaches to Crop Improvement, Karachi, Pakistan.

KALTSIKES, P. J., LUKASZEWSKI, A. P. AND GUSTAFSON, J. P. 1983. The effect of telomeric heterochromatin on chromosome pairing in several wheat-Secale hybrids. Proc. 6th Inter. Wheat, Genet. Symp., Kyoto, Japan, pp. 885-888.

KALTSIKES, P. J., GUSTAFSON, J. P. AND LUKASZEWSKI, A. J. 1984. Chromosome engineering in triticale. Can. J. Genet. Cytol, 26, 105-110.

LACADENA, J. R. 1967. Alloplasmic rye. Cytogenetic considerations about its obtention. Portug. Acta Bio., Ser. A-X, 1-2, 129-142.

LAMM, R. 1936. Cytological studies on inbred rye. Hereditas, $22,217-240$

LELLEY, T. 1976. Effect of nulli/tetrasomic combinations of wheat chromosomes in triticale. Z. Pflanzenzüchtg., 77, 89-99.

LELLEY, T. AND LARTER, E. N. 1980. Meiotic regulation in triticale: Interaction of the rye genotype and specific wheat chromosomes on meiotic pairing in the hybrid. Can. J. Genet. Cytol., 22, 1-6.

MERKER, A. 1976. The cytogenetic effect of heterochromatin in hexaploid triticale. Hereditas, 83, 215-222.

MÜNTZING, A. 1957. Cytogenetic studies in rye-wheat (Triticale). Cytologia (suppl.), pp. 51-56.

NARANJO, T. AND LACADENA, J. R. 1980. Interaction between wheat chromosomes and rye telomeric heterochromatin on meiotic pairing of chromosome $1 \mathrm{R}$ of rye in wheat-rye derivatives. Chromosoma, 81, 249-261.

NARANJO, T., LACADENA, J. R. AND GIRALDEZ, R. 1979. Interaction between wheat and rye genomes on homologous and homeologous pairing. Z. Pflanzenzüchtg., 82, 289-305. 
RILEY, R. AND CHAPMAN, v. 1957. The comparison of wheatrye and wheat-Aegilops amphidiploids. J. Agric. Sci., 49, 246-250.

REES, H. 1955. Genotypic control of chromosome behaviour in rye. I. Inbred lines. Heredity, 9, 93-116.

ROUPAKIAS, D. G. AND KALTSIKES, P. J. 1977. The effect of telomeric heterochromatin on chromosome pairing of hexaploid triticale. Can. J. Genet. Cytol, 19, 543-548.

SCHLEGEL, R. 1979. The effect of heterochromatin on chromosome pairing in different amphiploid wheat-rye hybrids. Cereal Res. Comm., 7, 319-327.
STUTZ, H. C. 1972. On the origin of cultivated rye. Am. J. Bot., $59,59-70$.

THOMAS, J. B. AND KALTSIKES, P. J. 1974. A possible effect of heterochromatin on chromosome pairing. Proc. Nat. Acad. Sci. USA, 71, 2787-2790.

THOMAS, J. B. AND KALTSIKES, P. J. 1976. The genomic origin of the unpaired chromosomes in triticale. Can. J. Genet. Cytol., 18, 687-700. 